\title{
AC 2008-1816: AN INTRODUCTORY MATERIALS COURSE: MAKING CONCRETE STAND UP TO THE TASK
}

\section{David Cottrell, University of North Carolina at Charlotte}

DR. DAVID S. COTTRELL is an Assistant Professor in the Department of Engineering Technology, University of North Carolina at Charlotte. He graduated from the United States Military Academy in 1978 and retired in 2000 after more than 22 years of service with the US Army Corps of Engineers. Studies at Texas A\&M University resulted in an MS Degree in Civil Engineering in 1987 and a $\mathrm{PhD}$ in 1995. He is a registered Professional Engineer and has taught courses in statics, dynamics, mechanics of materials, graphic communications, engineering economy, and construction planning, scheduling, estimating, and management. 


\section{An Introductory Materials Course: Making Concrete Stand Up to the Task}

\section{Introduction}

In recent years, much has been written about the many potential benefits resulting from a freshman-level "Introduction to Engineering" or "Introduction to Materials" courses. Despite these benefits, however, many institutions have been unable to add such a course to their engineering curricula, for a variety of legitimate reasons. At the University of North Carolina at Charlotte, the creation of a new program in Construction Management allowed for the development of a new curriculum including a new course on construction materials. Primarily intended for $1^{\text {st }}$ year students, this introductory course - ETCE 1222, "Construction Materials" - studies the history, physical properties, behavior, and application of basic construction materials. The course format features two 75-minute lectures and a 3-hour laboratory each week. Selecting Basic Construction Materials, 7th Edition, by Theodore W. Marotta as the course text, topics included mineral aggregates, Portland cement concrete, masonry, wood, asphalt concrete, metals, plastics, and other materials.

This paper focuses on a block of instruction interior to the course that introduces students to the preparation, testing, and properties of Portland cement. Implementing a methodology generally consistent a project based learning approach, the students worked in teams to explore real-world problems involving mixing, placing, curing, and testing of concrete. It is widely held that project based learning contains two essential components: (1) a driving question or problem that serves to organize and drive activities, which taken as a whole amounts to a meaningful project; and (2) a culminating product(s) or multiple representations as a series of artifacts, personal communications, or consequential tasks that meaningfully addresses the driving question. ${ }^{1}$ In this project, the students were challenged to examine a commercially available "ready-to-use" concrete mix and determine if the detailed mix instructions provided by the manufacturer represented a reasonable formula for producing concrete with the specified compressive strength. The project envisioned a deliberate procedure where student groups would individually mix a batch of concrete that differed primarily by the amount of water added. Analysis included the testing of concrete cylinders at seven (7) and twenty-eight (28) days for accrued strength as well as observations of a number of concrete characteristics such consistency, workability, mixture homogeneity, and consolidation. Finally, the project culminated in the submission of a detailed lab report where the students chronicled what they had learned. Project based learning is associated with some distinctive benefits when compared to learning solely from textbooks including a deeper knowledge of subject matter, increased self-direction and motivation, improved research and problem-solving skills, and understanding how classroom learning connects to jobs and careers. ${ }^{2}$ This paper provides actual results and analysis from the students completing the concrete project portion of this course, but objective assessment of these benefits was not performed. Future research will address the effectiveness of this effort in terms of traditional project based learning benefits. 


\section{Course Learning Outcomes Concerning Portland Cement}

The portion of the course dealing with Portland cement included both traditional classroom instruction as well as the laboratory experiences presented in this paper. The subset of the Course Learning Outcomes regarding Portland cement is rather well developed and deals particularly with understanding the nature and application of Portland cement; it includes the following:

1. Appreciate the historical development of concrete and its current physical composition.

2. Understand the basic steps in producing Portland cement. (Refer to www.cement.org/basics/images/flashtour.html for audio-visual presentation.)

3. Understand the process of hydration and its critical role in achieving compressive strength.

4. Appreciate the properties of concrete including fineness and soundness.

5. Appreciate the basic procedures involved in concrete operations including site prep, erecting form work, placing re-steel, placing concrete, and finishing and curing.

6. Recognize the standard tests for concrete include slump tests, test cylinders, and non-destructive tests.

7. Recognize the critical necessity of joints in concrete operations; identify the three basic types of joints and their utility (contraction joint, isolation joint, and construction joint).

8. Employing the procedure in ACI 211.1-91, design a concrete mix satisfying a specified compressive strength and design profile.

9. Compressive Strength:

a) Understand the historical basis and the limitations of computing the required compressive strength.

b) Compute the strength for a concrete mix with standard testing data considering modification of the standard deviation as appropriate.

10. Curing.

a) Understand the process of curing and some of the critical factors influencing the resulting compressive strength including minimal $\mathrm{w} / \mathrm{c}$ ratio, hydration, available moisture, and temperature.

b) Understand the standard curing techniques of water curing and sealed curing.

c) Recognize special situations requiring potentially extraordinary techniques for curing including mass concreting, hot-weather, and cold weather.

These outcomes are directly incorporated into lectures, but during five separate laboratory periods of approximately three (3) hours in length, project based learning reinforces through 
hands-on activities mixing, placing, curing, and testing concrete. In the paragraphs below, the author describes the laboratory objectives and the details of an experimental procedure with Portland cement that is simple in application but far-reaching in its ability to demonstrate the fundamental properties of concrete.

\section{The Labor atory Objectives and Procedures}

Classroom instruction provides the basic characteristics of concrete but the laboratory project provides the opportunity for the students to verify theory though hands-on practice and application. Laboratories employ industry-accepted techniques used to design, measure, and mix a batch of concrete, place and cure test cylinders, perform compressive tests to determine the 7 and 28-day strengths, and assess the long term performance of exposed concrete. To simplify lab

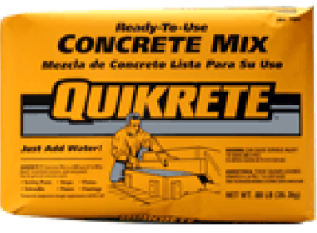

Figure 1: The "Ready-ToUse" Concrete Mix Employed during the Concrete Lab Project procedures and keep student effort within the defined scope of an introductory course, students used a commercially available "ready-to-use" concrete mix such as the one shone in Figure 1 to conduct their lab. (See http://www.quickrete.com/ for more detailed information of the product description, specifications, and uses.) The project scope included the following intermediate objectives which encompass several standard concrete procedures:

- Preliminary analysis: Students initially examined the concrete mix to predict the resulting compressive strength as intended by the designer. Visual inspection of the contents allowed to students to positively identify the base components - sand, coarse aggregates, and Portland cement. The instructions contained on the bag indicated that with the addition of 0.75 gallons of water, the resulting concrete should develop a final compressive strength of 4,000 pounds per square inch (psi).

- Batching: Lab participants were divided into small groups of three to four students; each group batched a small amount of wet concrete using a different amount of water. The exact procedure is detailed later in this paper.

- $\quad$ Slump Test: Performance and analysis included the standard slump test (in accordance with the American Society for Testing and Materials (ASTM) C-143, "Standard Test Method for Slump of Hydraulic-Cement Concrete"3). The ASTM C143 test for slump of Portland cement concrete details the procedure for performing slump tests on fresh concrete. The slump test is the simplest and most commonly used test for consistency and workability of the concrete. The freshly mixed concrete is packed into a $300 \mathrm{~mm}$ ( $12 \mathrm{in}$.) high cone, $200 \mathrm{~mm}$ ( $8 \mathrm{in}$.) wide at the bottom and $100 \mathrm{~mm}$ (4 in.) wide at the top, which is open. The concrete is smoothed off level with the top rim of the cone, and the cone is then carefully lifted, so that the concrete is left unsupported. The slump is the distance that the centre of the cone top settles. In a so-called 'true' slump test the base of the concrete does not spread excessively. If the concrete collapses or shears to one side the test results will be unreliable. 
Although the slump test does not directly measure the work needed to compact the concrete, it gives a reasonable indication of the how easily a mix can be placed and is simple to perform. The test is only suitable for reasonably workable, cohesive mixes. Very stiff mixes do not settle enough for useful measurements to be made and noncohesive mixes tend to shear or collapse. A slump of less than $25 \mathrm{~mm}$ (1 in.) indicates a stiff concrete and a slump of more than $125 \mathrm{~mm}$ (5 in.) indicates a very runny concrete. ${ }^{4}$ Along with the recorded slump of each mix, students made and recorded observations regarding concrete consistency, workability, mixture homogeneity, and consolidation.

- Casting: Each group prepared two cylinders in accordance with established techniques and procedures as specified in ASTM C31, the test procedure for making compressive tests cylinders. ${ }^{5}$ The standard test cylinder is 6 inches in diameter by 12 inches high for aggregates up to 2 inches. For larger aggregates, the diameter should be at least three times the aggregate size and the height at least twice the diameter. ${ }^{6}$ For smaller aggregates less than 1/3 inches, a smaller test cylinder of 4 inches in diameter is acceptable; this lab falls into this latter category. Cylinders are stored in a controlled, moist curing room for later testing.

- $\quad$ Testing: Each group performed a 7-day and a 28-day compressive test to determine the respective strength of the cured concrete on their respective cylinders. Procedures were in accordance with ASTM C $-873^{7}$ standard testing methods for concrete which covers determination of compressive strength of cylindrical concrete specimens such as molded cylinders and drilled cores. Analysis includes data for all of the cylinders from all lab groups allowing assessment of not only the evolution of increased strength through the initial 4 weeks but also strength as a function of the amount of water originally added to the mix and consequently the effect of the waterto-cement ratio on compressive strength.

- $\quad$ Long Term Endurance: The final lab included a walking "tour" about campus to inspect existing concrete and masonry structures (sidewalks, foundations, walls, etc.) Students took photographs and hypothesized based on their research concerning the observed condition of concrete structures.

\section{The Procedure for Batching the Concrete and Modifying the Water Cement Ratio}

As previously discussed, the lab employed a ready-to-use "Quikrete" concrete mix that contains predetermined proportions of Portland cement, sand, and coarse aggregate. The manufacturer's instructions on the 80 -pound sack indicated that the addition of $3 / 4$ gallon of water for one sack would achieve a mix design compressive strength of 4,000 psi. With this information as a backdrop, the following procedure was developed to test the design and its susceptibility to the addition of varying amounts of mix water. Classroom instruction had already described the process of hydration and the theoretical inverse relationship between the water-cement ratio and compressive strength. Therefore, the project envisioned multiple successive mixes each with a unique quantity of mix water that would theoretically yield a different compressive strength. 
Administratively, the course divided the approximately 80 students into four separate lab sections which were subsequently sub-divided further into six lab groups of three to four students. The lab objectives noted above were executed though the following procedures:

- Group 1 Procedures: The first lab group began the laboratory by mixing a singular batch of concrete as recommended by the manufacturer - that is, adding only $3 / 4$ gallon of water per 80-pound sack. They performed a slump test and recorded detailed observations concerning consistency, workability, mixture homogeneity, and consolidation. This group casted two cylinders supporting subsequent seven and twenty-eight day compressive strength tests. All appropriate testing procedures for sampling and handling of the cylinders were strictly enforced to ensure reliability of the test.

- Group 2 Procedures: As the second lab group assumed control of the concrete mixture, they added an additional $1 / 2$ pint of water for each sack of the ready-mix used originally in the batch. After thoroughly remixing the batch to ensure consistency, the lab group performed a slump test and recorded detailed observations concerning consistency, workability, mixture homogeneity, and consolidation. This group then also casted two cylinders for seven and twenty-eight day compressive tests. All appropriate testing procedures for sampling and handling of the cylinders were strictly enforced to ensure reliability of the test.

- Groups 3, 4, 5, and 6 Procedures: Each subsequent lab group in turn followed the precedent of the second group by adding in turn $1 / 2$ pint of water for each sack of ready-mix used originally in the batch by the first group. After thoroughly remixing the batch to ensure consistency, each lab group successively performed a slump test and recorded detailed observations concerning consistency, workability, mixture homogeneity, and consolidation. Each group then casted their two respective text cylinders to support seven and twenty-eight day compressive tests.

As this procedure was followed, each lab section produced six pairs of test cylinders with six unique water-cement ratios respectively. This procedure was repeated in each of the four lab sections. All cylinders were moist cured for the appropriate amount of time to support seven and twenty-eight day compressive strength tests. The results of the test are presented below.

\section{Project Experimental Results}

With four lab sections, the lab generated four complete data sets corresponding to the six different designs based on an ever increasing water-cement ratio. Experimental results were consolidated and shared so that each lab had access to the total data set. For each of the six water-cement ratios incorporated into the mix design, students averaged the four data points for the respective seven and twenty-eight day strengths so that the data was reduced to six sets of seven and twenty-eight day strengths (See Table 1). Graphical presentations plotted the 
results connecting the respective data points with equivalent water-cement ratios for easy comparison and analysis.

As part of the lab commentary included in their lab reports, students were challenged to describe the adequacy of the project in confirming the theoretical properties of concrete including:

- The progression of concrete from a 7-day strength to a 28-day strength and

- The reduction in strength resulting from adding more water to each design (thus increasing the water-cement ratio).
Table 1: Averaged Results from the Concrete Laboratory

\begin{tabular}{ccc}
\hline & \multicolumn{2}{c}{$\begin{array}{c}\text { Average } \\
\text { Compressive } \\
\text { Strength (psi) }\end{array}$} \\
Mix & 7-day & 28-day \\
\hline 1 & 2023 & 1911 \\
2 & 3425 & 4289 \\
3 & 3485 & 4146 \\
4 & 3269 & 4032 \\
5 & 2832 & 3687 \\
6 & 2415 & 3205 \\
\hline
\end{tabular}

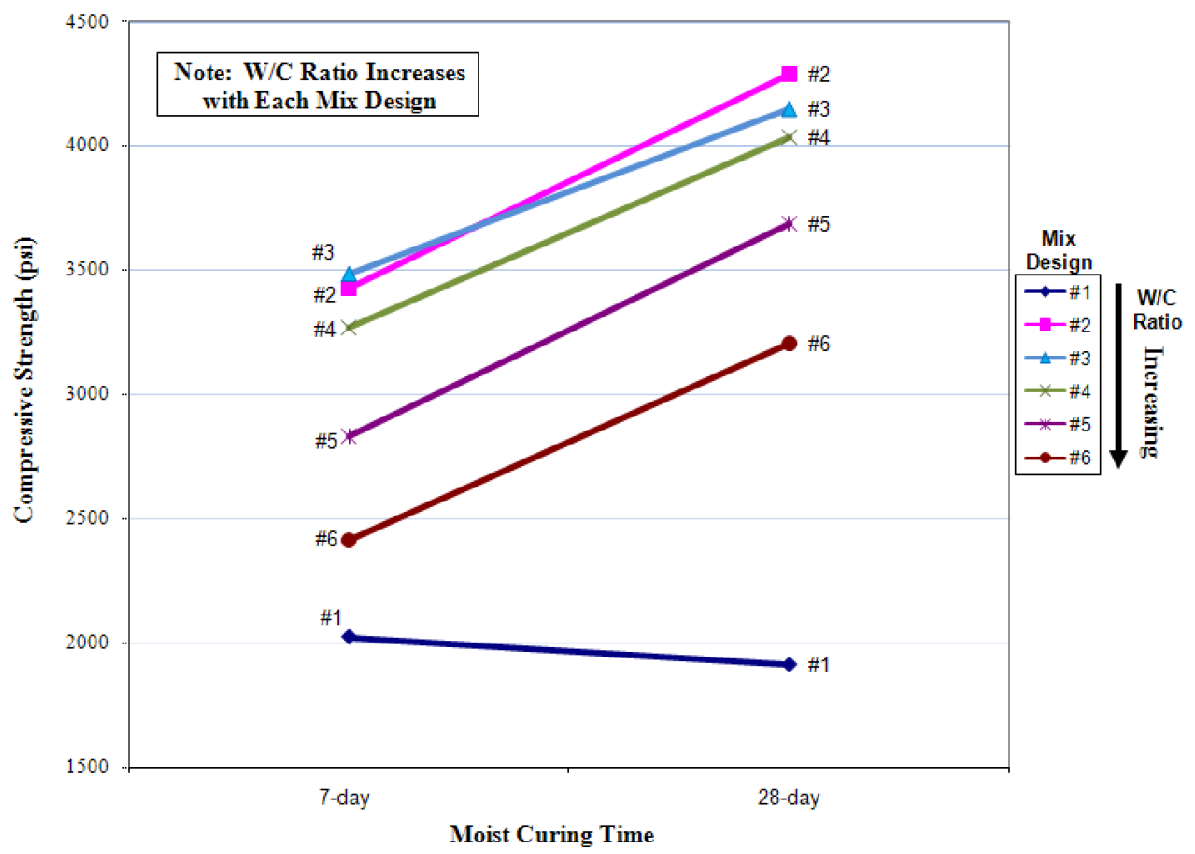

Figure 2: Experimental Results from the Concrete Laboratory from ETCE 1222, Construction Materials.

The project was considered generally successful in accomplishing the stated objectives. However, as Figure 1 shows, the data clearly exhibited an anomaly in the concrete design. The first mix design with $3 / 4$ gallon of water per sack - ironically, the quantity recommended by the manufacturer - failed to generate the expected strength; it also did not apparently exhibit the expected strength gain from 7 to 28 days. Most students made appropriate observations that the initial design simply failed to provide enough water to permeate the 
materials of the mix and to support proper hydration. This observation was further corroborated with reports of "stiffness" and extremely low workability associated with this initial mix. Other results from designs that included higher quantities of water in the mix design, however, clearly supported the expected, theoretical downward trend in strength commensurate with increasing the water in the design. Further, the increase in strength from seven to twenty-eight days was pronounced.

Subjectively, this particular portion of the course emerged during end-of-semester student critiques as particularly popular and enjoyable. For many students, this was their first exposure to concrete and in their words, "getting dirty" rendered the topics not only fun but real. One student wrote, "We made, we broke it, we analyzed it - this is engineering!" Student comments tended to affirm the practice of corroborating not just in small groups but also as a collective, sharing data and insights with students in other sections throughout the course.

\section{Conclusion}

This paper testifies to the possible utility of implementing project based learning in a freshman-level materials course. At the University of North Carolina at Charlotte, the Civil Engineering Technology and Construction Management curriculums include a new freshman course exploring construction materials. This introductory course - ETCE 1222,

"Construction Materials" - studies the history, physical properties, behavior, and application of basic construction materials. This paper focused on a block of instruction interior to the course that introduces students to the preparation, testing, and properties of Portland cement. This paper provided actual results and analysis from the students completing the concrete project recently executed as a portion of this course. This project based, experimental procedure with Portland cement was simple in application but far-reaching in its ability to demonstrate the fundamental properties of concrete. Certainly, this paper provides positive evidence highly supportive not only of the future development and implementation of freshman-level engineering courses but also implementation of project based learning in engineering.

Bibliography:

1. "Houghton Mifflin's Project Based Learning Space," http://college.hmco.com/education/pbl/background.html, Feb 29, 2008

2. "Priority Topic: Project Learning - Innovative Teaching in K-12 Schools, Edutopia, The George Lucus Education Foundation, http://www.edutopia.org/projectbasedlearning, Feb 29, 2008.

3. The American Society for Testing and Materials (ASTM) C-143/C143M-05a, "Standard Test Method for Slump of Hydraulic-Cement Concrete"," ASTM International, 100 Barr Harbor Drive, West Conshohocken, PA 19428, Nov 1, 2005.

4. Marotta, Theodore W., Basic Construction Materials, $7^{\text {th }}$ Ed., Prentice Hall, Upper Saddle River, New Jersey, page 187. 
5. The American Society for Testing and Materials (ASTM) C-31/C31M - 06, "Standard Practice for Making and Curing Concrete Test Specimens in the Field," ASTM International, 100 Barr Harbor Drive, West Conshohocken, PA 19428, 2006.

6. Marotta, Theodore W., Basic Construction Materials, $7^{\text {th }}$ Ed., Prentice Hall, Upper Saddle River, New Jersey, page 190.

7. The American Society for Testing and Materials (ASTM) C-873 - 04, "Standard Test Method for Compressive Strength of Concrete Cylinders Cast in Place in Cylindrical Molds," ASTM International, 2004. 